\title{
TRISTAN VIGLIANO, Parler aux Musulmans. Quatre intellectuels face à l'Islam à l'orée de la Renaissance
}

\section{Concetta Cavallini}

\section{(2) OpenEdition}

\section{Journals}

\section{Édition électronique}

URL : https://journals.openedition.org/studifrancesi/11679

DOI : $10.4000 /$ studifrancesi. 11679

ISSN : 2427-5856

\section{Éditeur}

Rosenberg \& Sellier

\section{Édition imprimée}

Date de publication : 1 avril 2018

Pagination : 118

ISSN : 0039-2944

\section{Référence électronique}

Concetta Cavallini, « TRISTAn viglano, Parler aux Musulmans. Quatre intellectuels face à I'Islam à l'orée de la Renaissance », Studi Francesi [En ligne], 184 (LXII | I) | 2018, mis en ligne le 02 juillet 2018, consulté le 15 novembre 2021. URL : http://journals.openedition.org/studifrancesi/11679 ; DOI : https://doi.org/ 10.4000/studifrancesi. 11679

Ce document a été généré automatiquement le 15 novembre 2021.

\section{(c) $($ ) $(9)$}

Studi Francesi è distribuita con Licenza Creative Commons Attribuzione - Non commerciale - Non opere derivate 4.0 Internazionale. 


\title{
TRISTAN VIGLIANO, Parler aux
}

\section{Musulmans. Quatre intellectuels face à l'Islam à l'orée de la Renaissance}

\author{
Concetta Cavallini
}

\section{RÉFÉRENCE}

TRISTAN VIGLIANO, Parler aux Musulmans. Quatre intellectuels face à l'Islam à l'orée de la Renaissance, Genève, Droz, 2017, 384 pp.

1 Le beau livre de Tristan Vigliano est une première réponse à «une sorte de lacune dans la recherche, pourtant riche, sur les liens entre le monde chrétien d'Europe occidentale et le monde musulman» (comme le reconnaît l'auteur dans l'Avant-propos, p. 10). Le livre de Vigliano ne se veut pas un livre destiné exclusivement aux spécialistes, mais il est aussi un livre de divulgation. En s'appuyant sur des études de référence, Vigliano prouve que le Moyen Âge se fait une idée presque toujours polémique sur l'Islam. L'analyse envisage l'Islam uniquement du point de vue religieux et non culturel, et sans tenir compte des projections contemporaines nées de la juxtaposition entre religion chrétienne et islam. La curiosité et la fascination exercées par l'Islam sur le monde occidental n'ont jamais manqué; cependant, la Chrétienté s'est toujours vue comme une identité religieuse et culturelle menacée. Vigliano se dit étonné que les études de référence comme celle de Norman Daniel (Islam et Occident) et de John Tolan (Les Sarrasins. L'islam dans l'imagination européenne au Moyen Âge) se concentrent uniquement sur le Moyen Âge, sans prendre assez en compte la Renaissance. Vigliano décide de prendre en considération et d'approfondir les figures de quatre auteurs, Jean Germain, Pie II, Nicolas de Cues et Jean de Ségovie qui ont effectué, chacun à sa manière, dans les années qui vont de 1451 (année où Germain achève le Débat du Chrétien et du Sarrasin) à 1461, année de composition de la Lettre à Mehemet II, une lecture de cette religion. Ces quatre auteurs qui se connaissaient et qui ont eu aussi des intérêts personnels en 
commun, ont effectué une réflexion portant à une connaissance plus profonde de l'altérité musulmane. Il faut remarquer que les quatre auteurs étaient évêques ou membres du clergé catholique à plusieurs titres; il s'agissait donc d'écrivains «engagés». Chaque chapitre de Vigliano s'ouvre par un paragraphe consacré à la biographie des auteurs qu'il traite, car son but est d'envisager les œuvres à partir aussi $\mathrm{du}$ contexte de production. L'analyse des ouvrages se fonde sur des citations ponctuelles et sur un apparat critique important, développé dans une bibliographie riche et approfondie (pp. 355-377) qui se trouve en fin de volume. Les citations, souvent tirées de manuscrits, comme dans le cas du manuscrit de Jean Germain rédigé pour le duc de Bourgogne Philippe le Bon, ont été réadaptées, surtout dans leur ponctuation, à l'usage moderne. De même, les textes des trois autres ouvrages, rédigés en latin, sont donnés en traduction (avec le texte latin en note).

2 Les deux événements historiques marquants, la prise de Constantinople par les Ottomans en 1453 et le concile de Bâle, qui a vu les quatre hommes d'Église engagés à plusieurs titres, servent de toile de fond à l'analyse des quatre ouvrages, les débats de Germain et la Lettre de Piccolomini, futur pape Pie II, qui est, selon certains, un simple morceau de rhétorique sans aucune véritable finalité diplomatique. Les deux écrits du cardinal allemand Nicolas de Cues, De pace fidei (1453) et Cribratio in Alkorani (1460-61) sont représentatifs d'un manque de volonté dialogante avec l'Islam. En effet, la religion de Mahomet est vue à l'intérieur d'un dessein de la Providence pour ramener les 'infidèles' à la vraie religion, la religion chrétienne. L'approche de Nicolas de Cues diffère de celle de Jean de Ségovie, qui a entretenu une correspondance suivie avec les trois autres écrivains présents dans le livre de Vigliano. Il a retraduit le Coran en latin, après la traduction problématique et souvent fautive de Robert de Ketton, et a entretenu un véritable dialogue avec des musulmans.

Cet intéressant volume de Vigliano traduit le besoin des chercheurs en identifiant un domaine qui mériterait d'être encore approfondi. Une analyse de la question pendant les années qui vont de la fin $d u \mathrm{xv}^{\mathrm{e}}$ à la fin $\mathrm{du} \mathrm{xvI}^{\mathrm{e}}$ siècle serait aussi utile. Les Sarrasins, comme on les appelait à l'époque, et leurs rapports militaires, économiques, politiques avec la Chrétienté, ont déterminé le cours de l'histoire entre la prise de Constantinople et la fin de la Renaissance. La curiosité à l'égard de leur religion était profonde et le nombre de traités, de lettres, de textes consacrés à la question a été important. Faire le tri entre ces textes, les classer, les analyser, n'est pas simple, surtout quand ils furent rédigés sans connaître la langue de départ et se fondent donc sur des malentendus, surtout linguistiques, évidents. Le mérite de Vigliano est donc d'avoir indiqué un parcours, de l'avoir entrepris par un volume rigoureux et cohérent. Nous espérons tous qu'il continuera ce parcours. 